\section{International Universities in the Arab World: What is Their Place?}

LISA ANDERSON

Lisa Anderson is former president of the American University in Cairo, and senior research fellow at New York University Abu Dhabi. E-mail: la8@columbia.edu.

A merican universities in the Arab world have long enjoyed a good-humored debate about whether they are in or of the city in which they are located. The American University in Cairo is in the minority; most-the American Universities of Beirut, Sharjah, Kuwait, and Iraq, for example-are of their place. It is not just an American question, although most non-American universities have settled on being in their cities, like the German University in Cairo, while international branch campuses often duck the issue, using a space (NYU Abu Dhabi), colon (Northwestern University: Qatar campus), or an entirely different preposition (Texas A\&M University at Qatar).

Beneath the lighthearted terminological dispute is a serious question: what is the place of universities with such explicit international affiliations in the Arab world today?

\section{Where They Come From}

The oldest of these institutions reflect a missionary impulse: the American University of Beirut (AUB) began in I866 as the Syrian Protestant College. Before it was established in I9I9, the trustees of the American University in Cairo (AUC) briefly called it Cairo Christian University. By the time AUC opened, however, the explicitly religious purpose of these universities was already giving way to a secular, if paternalistic, commitment to promoting education for moral character and enlightened citizenship.

The middle of the twentieth century saw the establishment of national universities across the Arab world to produce the administrative cadres of new and ambitious states. Private tertiary education was virtually unknown except in Lebanon, and free public higher education became a pillar of the developmental states of the region. Like the states themselves, however, government universities soon grew inefficient, underfunded, and ineffective, failing to meet the needs of the fast growing population. (Ultimately, youth unemployment would be higher in the Arab states than anywhere else in the world, estimated today at more than 30 percent.) In confronting this challenge, as in so much else, governments in the region turned to the private sector: 70 percent of the approximately 600 universities in the region today were established after I990, and about 40 percent of those are private, accounting for about 30 percent of the region's university enrollments. And, in the era of neoliberal globalization, the private sector turned to the world.

Thus, many of the private universities in the Arab world advertise themselves as attached to, modeled on, or otherwise associated with international establishments. In the United Arab Emirates alone, there are nearly 40 institutions that bear names identifiably American, European, or Australian. Some are cleverly marketed vocational schools and training institutes, but a substantial number are genuine efforts to provide a reasonably good undergraduate education, often drawing on the American liberal arts tradition. Some aspire to support serious graduate and research programs, as their efforts to win international-often American-accreditation attests. Similarly, the establishment of branch campuses, particularly in the Gulf-from the outposts of Carnegie-Mellon's engineering programs and Georgetown's School of Foreign Service in Qatar's Education City, to New York University's branch campus in Abu Dhabi (NYUAD), for example-and ambitious initiatives like Saudi Arabia's King Abdullah University of Science and Technology (KAUST), would all seem to be promising signs of investment in bringing international faculty, curricula, pedagogy, and governance practices to education and research in the region.

\section{Beneath the lighthearted terminologi- cal dispute is a serious question: what is the place of universities with such explicit international affiliations in the Arab world today?}

\section{What ThEY Do}

Yet, the extent to which these universities could play the catalytic role envisioned for them was always an open question. Obviously, they will never meet the regional demand for literally millions of new university places. Yet, as models for local universities, whether public or private, they often represent technology transfer at its most inauspicious, since the barriers to widespread adoption of the purposes, policies, practices, and products of these universities are virtually insurmountable.

To start, the language of instruction in international universities (even the region's German universities) is English, which both ensures they can recruit distinguished international faculty and restricts their local student applicant 
pool dramatically. These international faculty, whose reputations rest on the assessments of academic peers around the world, naturally publish their research in English, limiting its exposure in the region. They strive to meet the specialized standards of their disciplines and fields, selecting research questions and methods with an eye toward academic tastes and techniques, as measured in all-important citation indexes and impact factors, rather than harder-tomeasure social value or public consequence. The universities in turn reward these well-published faculty because their work contributes to raising institutional rankingsand high rankings draw funding, applications, government approvals, and international esteem. In the self-contained system of global higher education, it all makes sense.

\section{What They Do Not Do}

But from the regional perspective, this also means a chasm between the international institutions introduced to improve higher education in the Arab world and the societies they were supposed to benefit. In fact, the audience for these universities-their applicants, the visitors to their oncampus art exhibitions and musical performances, the employers of their graduates, their alumni and donors-is a cosmopolitan elite quite distant from the communities outside their walls, more comfortable in New York or London than downtown Cairo or suburban Beirut. Indeed, because they are often intended to anchor new development-technology hubs, new residential areas, cultural centers-some of these university campuses are closer to the nearest international airport than they are to the urban centers whose names they bear.

And, today, this isolation is exacerbated by the collapse of the popular uprisings of $201 \mathrm{I}$ throughout the Arab world in brutal restorations and vicious civil wars. After all, few host governments want their foreign guests in harm's way, while among the universities themselves there is little appetite for risk taking. Thus, from Cairo to Beirut, Doha to Dubai, universities increasingly look past the region to a global horizon that seems both more promising and less perilous. Some of the long-established institutions still note their regional foundations: AUB declares among its purposes "to serve the peoples of the Middle East and beyond." AUC is "dedicated to making significant contributions to Egypt and the international community(...)" The American University of Sharjah, one of the Emirates' oldest international universities, is "grounded in the culture of the Gulf region." But many others are far less securely anchored in their locale. The American University of Iraq prepares its students for "a modern, pluralistic society and a global environment." NYUAD equips its students "for the challenges and opportunities of our interconnected world." The American University of Kuwait simply "enriches society."
There is much to be said for providing the best possible education for the global elite to whom we entrust our future. But, as our bewilderment about the Arab world today suggests, that education will be incomplete if it is not grounded in-or born of, or even aimed at-the cities and communities where its institutions are located.

\section{A Chinese Branch Cam- pus in Malaysia-Adjusting Fundamentals}

\section{Bonnie Yingfei He and Alan Ruby}

Bonnie Yingfei He is beginning a career in international education and intercultural communication. E-mail: yingfeih16@gmail.com. Alan Ruby is a senior scholar at the University of Pennsylvania's Graduate School of Education, US. E-mail: alanruby1@gmail.com.

$X$ iamen University Malaysia (XMUM) opened in February 2016 , describing itself as "the first overseas campus established by a renowned Chinese university and the first Chinese university branch campus in Malaysia." The Malaysian government invited China's ministry of education to establish a branch campus to strengthen bilateral relations. Xiamen University (XMU) was chosen to lead the initiative because its founder, Mr. Tan Kah Kee, was a successful businessman in Malaysia, and the university has well-established programs in Southeast Asia studies and traditional Chinese medicine. XMUM is to be a not-for-profit entity, with any surplus revenues reinvested in research and student scholarships in Malaysia. The project is expected to cost US\$3I5 million and is being financed largely by a loan from the China Development Bank. Private donations helped with initial construction, including a US\$30 million gift for XMUM’s library.

\section{CONTEXT}

XMUM is of interest as the first branch campus of a Chinese university and its role as a flagship of China's international engagement strategy in higher education. A late entrant to a region with many branch campuses_nine in Malaysia and I4 in Singapore-XMUM offers some insights into how to attract enrollments in a well-served market-but a market where there have been failures, such as the withdrawals from Singapore of the University of New South Wales and New York University's Tisch School. How XMUM adjusts 